\title{
Internet na escola, escola na Internet.
}

\author{
DENISE BLANES \\ MÁRCIA PADILHA LOTITO \\ MíladA TONARELLI GonçALVES \\ PRISCILA GONSALES*
}

Em 2002, com o lançamento do EducaRede no Brasil (www.educarede.org.br), nascia uma experiência inovadora de inclusão social. Na atual sociedade da informação e do conhecimento, o investimento em educação ganha destaque quando assume o compromisso com o desenvolvimento pleno e com a oferta igualitária de oportunidades a todos os cidadãos.

Ao lançar seu Portal inteiramente direcionado ao atendimento da escola pública, a Fundação Telefônica apostou não só na ampliação do acesso de uma parcela expressiva da população à sociedade da informação, como também na formação de cidadãos capazes de lidar com as demandas das tecnologias digitais.

Guiados pela crença de que a inclusão digital constitui fator de eqüidade social, a Fundação Telefônica e seus parceiros brasileiros - CENPEC - Centro de Estudos e Pesquisas em Educação, Cultura e Ação Comunitária, Fundação Carlos Alberto Vanzolini e Terra Networks - assumiram o desafio de difundir o uso pedagógico da Internet por meio do EducaRede.

O Portal estrutura-se como um programa de educação que atua na capacitação de educadores e no desenvolvimento de projetos de mobilização e sensibilização

* Denise Neri Blanes é doutora em Serviço Social e analista de projetos do Instituto de Estudos Especiais da PUC-SP. É especialista e consultora na área de gestão, desenvolvimento, avaliação e monitoramento de programas e projetos sociais. MARCIA PADILHA foi coordenadora-executiva do EducaRede. É especialista no desenvolvimento de projetos com uso de Internet e de conteúdos digitais para educadores e jovens. É consultora da ONG Midiativa. MíladA TONARELLI GonçALVES é psicóloga e mestre em Ciências da Comunicação pela Universidade de São Paulo. Desde 2000, trabaIha como pesquisadora do Cenpec, no Programa EducaRede Brasil. PRISCILA GONSALES é jornalista, pós-graduada em Comunicação e Educação pela Universidade de São Paulo. Desde 2001, trabalha como pesquisadora do Cenpec, na coordenação do Programa EducaRede Brasil. de escolas, em parceria com governos locais. Em cinco anos de atividade, formou diretamente mais de dez mil professores e beneficiou 56 mil alunos da rede pública de ensino.

Este artigo apresenta a reflexão acumulada no período acerca de um dos temas mais importantes da educação contemporânea: a relação entre Internet e aprendizagem, com base no conceito de letramento digital, para detalhar e explicitar as aprendizagens favorecidas pelo uso da Internet na escola. A partir da reflexão conceitual, apresentam-se: a concepção da avaliação no EducaRede, os processos utilizados e a sua matriz avaliativa.

\section{Internet e aprendizagem}

\section{Os desafios enfrentados ao longo dos cinco primeiros} anos do EducaRede no Brasil resultaram em um conjunto de reflexões sobre a relação entre Internet e aprendizagem. Se o século XXI oferece a possibilidade de a www - world-wide web, a interface gráfica da Internet - enriquecer o modo de aprender e ensinar, é preciso problematizar sua relação com os processos desejáveis para a aprendizagem significativa e socialmente compartilhada, pensando de que maneira os meios tecnológicos podem favorecer a produção do conhecimento em contextos educativos.

No contexto da cultura das mídias, o professor, e até mesmo um especialista, perde a função de única fonte de informação. A dinâmica que se estabelece na sala de aula - ou no laboratório de Informática - marcada por atividades múltiplas e simultâneas, favorece o diálogo e a troca entre educadores e alunos, horizontalizando as relações.

Nesse cenário, cabe ao professor selecionar fontes de pesquisa, refletir criticamente sobre as informações 
...o papel do educador é

fundamental para estimular, nos alunos, uma ampla gama

de aprendizagens, além de

provê-los da orientação e do

apoio necessários para que

se tornem aptos a pesquisar,

publicar e interagir na

Internet com segurança, de

forma crítica e autônoma, dentro ou fora da escola

- questões que demandam

um processo de formação

continuada do próprio

professor.

encontradas, atribuir-lhes significados, contribuir para que os alunos identifiquem o que é relevante, orientar a publicação de trabalhos e qualificar a comunicação digital entre os alunos. Sua formação e experiência como educador the conferem condições para exercer o papel a que se tem exaustivamente chamado de professor-mediador.

A profusão de fontes de conhecimento e o aumento das oportunidades de comunicação ressaltam a centralidade do educador na proposição de desafios e contrapontos ao aluno. Para isso, contudo, é necessário que o professor entenda a Internet como instrumento cognitivo, sabendo equilibrar seu uso para tarefas em que ela realmente faça a diferença.

Ao aluno, coloca-se a oportunidade de assumir uma postura ativa na construção das habilidades necessárias para ter acesso às oportunidades que a Internet oferece. Assim, ao mesmo tempo em que fascina por ser uma poderosa ferramenta para o alargamento da ação educativa em novos espaços de aprendizagem, esse meio torna ainda mais complexas as tarefas de ensinar e aprender.

Em face disso, o papel do educador é fundamental para estimular, nos alunos, uma ampla gama de aprendizagens, além de provê-los da orientação e do apoio necessários para que se tornem aptos a pesquisar, publicar e interagir na Internet com segurança, de forma crítica e autônoma, dentro ou fora da escola - questões que demandam um processo de formação continuada do próprio professor.

\section{Ciberespaço e hipermídia}

0 mundo que se acessa ao entrar na Internet, chamado de ciberespaço, é formado por uma série de dados que aparece em forma de textos, sons ou imagens. Pode-se dizer que um de seus grandes diferenciais é o fato de a organização, a manipulação e a troca de informações dependerem da interação do usuário, que pode atuar de maneiras diferenciadas para obter resultados com os recursos disponiveis na Rede. A isso se chama "navegar".

Navegar é mais do que visitar passivamente um universo pré-definido de informações. Ao navegar, o internauta interfere no ciberespaço, reorganizando o fluxo de informações das quais ele é composto. Por isso, de certa forma, ele é um leitor-autor, pois, ao escolher suas ações na web com seus "cliques", interfere no modo, no tempo e na ordem com que as informações são apresentadas.

Do ponto de vista da educação, a navegação no ciberespaço pode ser compreendida como uma ação de aprendizagem exploratória e criativa, realizada de modo particular e reflexivo:

- exploratória porque permite ao aluno clicar livremente, ir e vir, repetir e experimentar caminhos;

- criativa e particular porque exige definição de critérios, regras e lógicas que auxiliam na construção do percurso e na obtenção de resultados significativos;

- reflexivo, pois, ao definir um método de navegação, o aluno deve analisar e readequar suas estratégias e seu raciocínio, ainda que de maneira informal.

Muitas possibilidades estão abertas no ciberespaço:

- comunicar-se por meio de ferramentas, como batepapos e fóruns;

- participar de grupos e comunidades virtuais;

- tornar-se autor de informações, por meio da criação de páginas e sites, sejam elas com recursos simples de textos ou envolvendo recursos de simulações e bancos de dados, entre outros.

Conhecer as diferentes ferramentas disponíveis no ciberespaço possibilita ao professor usar a Internet de forma consciente e personalizada. Além de seu potencial de pesquisa e de comunicação, a Internet é um importante instrumento cognitivo, que potencializa os processos de ensino e aprendizagem. Para tanto, é necessário que o professor compreenda e saiba usar esse meio, definindo com clareza os objetivos que pretende atingir, planejan- 
do como avaliá-los durante o processo, de preferência com a participação dos alunos.

\section{Quantidade e qualidade: uma conquista}

Desde a segunda metade do século XIX, a informação converteu-se em importante mercadoria. Se, por um lado, existe a tecnologia para tornar disponivel todo o conhecimento elaborado, por outro, a informação-mercadoria não favorece a construção do conhecimento, uma vez que é marcada por imediatismo, redundância de conteúdos, produtos de fácil e rápida leitura, pouco exigentes em termos de interpretação (Barato, 2005).

Nesse contexto, a enorme disponibilidade de dados exige habilidades de apreensão rápida e simultânea, além da capacidade de relacionar informações em um raciocínio disperso, movido por links. No entanto, o completo usufruto das informações impõe a necessidade de se recorrer cada vez mais à interpretação, à seleção e à crítica, ações que exigem concentração e análise.

Além da familiaridade com formas de comunicação difusas e com a diversidade de linguagens, análise e concentração são igualmente relevantes para a transformação da informação em conhecimento pessoal e significativo. As ferramentas são instrumentos para uso dos recursos de interatividade da Internet. Elas podem ser de:

- busca - pesquisa na Rede;

- comunicação - fórum, bate-papo;

- publicação - como a Oficina de Criação e a Galeria de Arte do EducaRede.

\section{Aprender a pesquisar}

Enciclopédias, dicionários, livros, websites, bancos de imagens, animações, vídeos... São tantas as informações disponíveis na Internet, em variados formatos e fontes, que não é difícil se perder entre as múltiplas janelas abertas do navegador, em uma espécie de labirinto digital. Nesse cenário, os novos modos de acessar e ler textos em enorme quantidade e codificados em diferentes linguagens tornam-se um grande desafio. Como chegar a algum lugar nesse labirinto? Como estabelecer unidade nesse universo de conexões? Como construir conhecimento nesse mar de informações?

Para que a pesquisa na Internet seja significativa no processo de construção do conhecimento do aluno, evitando o famoso "copiar e colar", é importante uma me- todologia focada no desenvolvimento de aprendizagens relacionadas a identificar e selecionar informações relevantes. Essas aprendizagens envolvem diversos recursos cognitivos, como levantamento de hipóteses, análise, comparação e síntese, e pressupõem outras habilidades - leitura de textos não-lineares, como hipertextos, e alfabetização nos códigos das linguagens do ambiente hipermídia.

\section{Hiperlink e hipertexto}

Uma característica marcante da Internet é o hiperlink, ligação que permite que se vá de um texto a outro, ou de uma parte de um texto a outra desse mesmo texto, por meio de palavras ou imagens interligadas. Com o hiperlink, constroem-se hipertextos - textos organizados para uma leitura não-linear, isto é, com várias possibilidades de percurso, conforme associações de idéias, direcionamento de interesse ou níveis de aprofundamento.

Desse modo, o leitor acessa conteúdos elaborados por outras pessoas, porém, criando a própria rota, um caminho que produzirá sentidos de acordo com a navegação individual.

Os links normalmente são planejados de modo a proporcionar ao leitor autonomia na escolha de direções, dentro de caminhos inicialmente previstos pelos autores daquele site ou documento. Além de ligarem trechos de um texto ou partes de um mesmo site, eles podem fazer a ponte entre vários sites.

Nos processos de ensino e aprendizagem, do ponto de vista individual, links e hipertextos possibilitam que o aluno tenha a liberdade de caminhar em sua pesquisa de acordo com seu interesse e seu ritmo. Do ponto de vista coletivo, é enriquecedor que o trabalho do grupo seja complementado pelos percursos individuais e diferenciados de cada aluno.

\section{Aprender a publicar}

Um recurso importante disponibilizado pela Internet é a possibilidade de publicar documentos de qualquer tipo (texto, som ou imagem) de forma organizada para o leitor. Pode-se publicar a partir de soluções sofisticadas ou simples, como as ferramentas para construção de sites pessoais ou blogs, voltadas especialmente para o público leigo. Essa facilidade torna a publicação na Internet uma ação bastante difundida nos dias de hoje. 
Do ponto de vista da educação, trata-se de uma oportunidade de incrementar as habilidades de comunicação entre os jovens, tornado-os produtores e editores de conteúdos próprios e de terceiros. Publicar na Internet é também uma forma de dar maior alcance aos produtos desenvolvidos na escola, oferecendo a alunos e professores a oportunidade de agir como promotores de cultura.

A publicação das atividades escolares no ciberespaço também é um canal para expressar as diferentes realidades, reafirmando questões de identidade, ao mesmo tempo que permite visualizar os contextos localizados e globalizados que caracterizam a atual era.

Para assegurar qualidade no uso educacional desse recurso, é necessário orientar os alunos a construir um significado próprio para a atividade de publicação de conteúdos na web, entendendo-a como uma oportunidade criativa de interferir em uma rede que congrega conhecimentos, diferentes modos de ver e de estar no mundo.

Para publicar algo, é necessário planejar o que será divulgado, definir tamanhos e tipos de documentos, a navegação entre eles, num trabalho que envolve produção e edição das informações. É preciso que o aluno tenha algo importante a dizer e a publicar e que se veja como autor de informações e produtor de conhecimento.

\section{Aprender a se comunicar digitalmente}

O caráter interativo da Internet é um dos distintivos mais notáveis dessa mídia. Embora o debate seja amplo entre estudiosos, pode-se dizer que a interatividade diz respeito à relação homem-máquina (ou homemsoftware) e à relação homem-homem, mediada pela máquina. Em seu primeiro aspecto, ela pode ser bastante simples, como nos casos de ação e reação em softwares de perguntas e respostas que indicam acertos e erros, ou complexa, quando o usuário modifica o conteúdo e a forma do ambiente no momento em que navega, em tempo real. 0 EducaRede adota a interação entre pessoas em processos de comunicação com o uso de computadores ligados à Internet.

Ambientes interativos como fóruns, salas de bate-papo e listas de discussão são os mais populares da Internet. Todos têm a finalidade de colocar grupos de pessoas em comunicação, mas as características de cada um os tornam mais adequados a este ou àquele tipo de uso. Eles representam uma oportunidade para os professores trabalha-

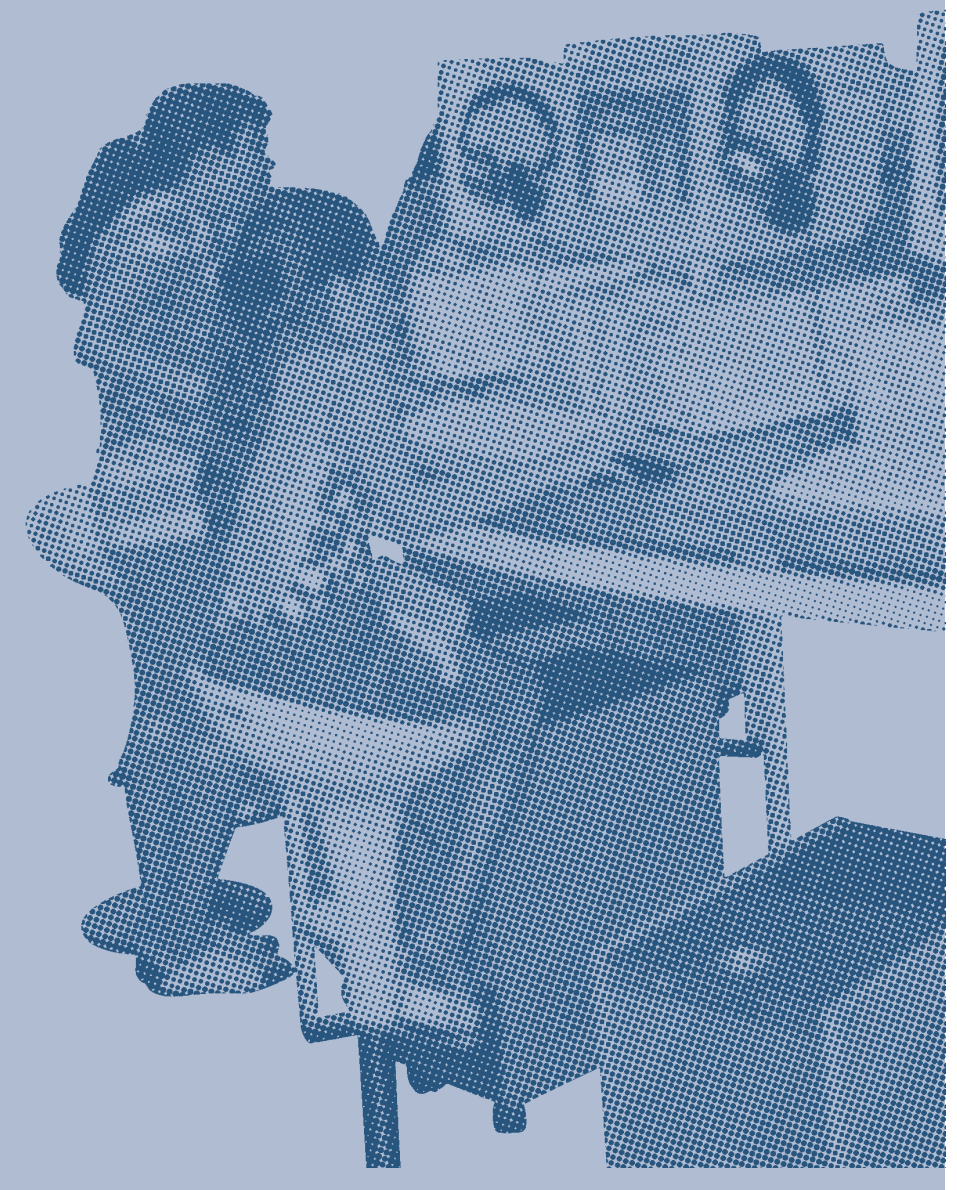

rem, com seus alunos, as habilidades de comunicação e expressão e suas particularidades no meio digital.

Os fóruns e bate-papos também têm um importante potencial para constituir novas aplicações pedagógicas. 0 fórum é um ambiente em que as mensagens podem ser postadas a qualquer momento, ficando registradas para leitura dos participantes do grupo. As mensagens são enviadas com o nome dos destinatários e geralmente ficam organizadas em listas de perguntas e respostas. Os participantes têm a liberdade para comentar mensagens já existentes ou inserir novas.

Por ser um ambiente em que os tempos de escrita e leitura não influenciam no fluxo da comunicação, os fóruns são adequados para a realização de debates e estudos aprofundados, com mensagens longas, sejam reflexivas ou descritivas.

Em relação às discussões presenciais, os fóruns em meio digital apresentam algumas vantagens para o uso pedagógico, como:

- registro completo das participações, facilitando o acompanhamento do professor e a análise das opiniões dos alunos;

- estímulo à escrita, como instrumento significativo de comunicação entre pares;

- valorização do papel do aluno, com o incentivo à participação dos mais tímidos;

- restrição da dispersão e da indisciplina, em razão da identificação das mensagens; 
- apoio à concentração e à análise necessárias à participação no ambiente.

0 bate-papo permite que pessoas se comuniquem em tempo real: os participantes trocam mensagens uns com os outros abertamente, sendo propiciado a todos acessar as mensagens enviadas. Há ambientes em que dois participantes podem conversar de modo reservado. A comunicação sincrônica é a principal marca das atividades desenvolvidas no bate-papo. A troca entre as pessoas é bastante dinâmica, assemelhando-se à conversa facea-face. A flexibilidade de encaminhamento do tema conforme o interesse do grupo também é maior. Do ponto de vista cognitivo, a velocidade de escrita das mensagens demanda a habilidade de síntese, para a elaboração de mensagens curtas e objetivas. A agilidade na leitura e na classificação das temáticas já abordadas é exigida para evitar a repetição desnecessária de mensagens.

Do ponto de vista social, cria uma auto-regulamentação no grupo, que demanda a adequação do tempo pessoal ao tempo do grupo, e a crítica em relação à intensidade da participação pessoal, viabilizando a participação de todos.

Em relação à conversa presencial, o bate-papo tem em comum com o fórum a mudança na dinâmica entre os alunos. Se for gravado, também engloba a qualidade do registro. Ambos desenvolvem leitura, escrita e comunicação em meio digital, embora com exigências de habilidades e competências distintas.

\section{Aprender em rede: comunidades virtuais}

Na construção coletiva, a Internet semeia novas possibilidades educacionais, novos processos e novas estruturas que estimulam, provocam e facilitam a colaboração, em que os saberes individuais são valorizados e contribuem para a construção, que é do grupo.

A rede é, antes de tudo, um instrumento de comunicação entre pessoas, um laço virtual em que as comunidades auxiliam seus membros a aprender o que desejam saber. Os dados não representam senão a matéria-prima de um processo intelectual e social vivo, altamente elaborado.

Enfim, toda a inteligência coletiva do mundo jamais dispensará a inteligência pessoal, o esforço individual e o tempo necessário para aprender, pesquisar, avaliar e se integrar a diversas comunidades, sejam elas virtuais ou não (Lévy, 1998, p. 2).
As comunidades virtuais

têm o potencial de gerar

mudancas nos processos

de ensino e aprendizagem,

nas formas de interação

entre quem aprende e quem

ensina e na relação com

o conhecimento, gerando

estratégias pedagógicas

inusitadas.

Comunidades virtuais são ambientes planejados para a realização de trabalhos em grupo na Internet. Podem apresentar recursos de pesquisa, de publicação e de comunicação digital, combinando ferramentas de registro de produtos e processos, de compartilhamento entre colegas, de comunicação síncrona e assíncrona.

Elas se estruturam conforme seus objetivos. Nas comunidades de troca de informações, participantes organizam-se para disponibilizar e obter informações sobre temas de interesse comum. Nas comunidades de aprendizagem, são estabelecidos objetivos, metas e um projeto pedagógico adequado para a construção colaborativa de determinado saber.

Do ponto de vista da escola, os ambientes virtuais têm possibilitado o desenvolvimento de metodologias enriquecedoras que podem combinar, de forma original e personalizada, os recursos de pesquisa, de comunicação digital e de compartilhamento de registros voltados ao trabalho colaborativo.

A ampliação do número e da diversidade de sujeitos em um ambiente virtual, devido à superação de barreiras de tempo e espaço, intensifica a necessidade de negociação de sentidos ou, em outras palavras, de vivência de conflitos sociocognitivos, fundamentais para os processos de aprendizagem.

É necessário compreender as comunidades virtuais e seu caráter colaborativo para utilizá-las com bom senso. Elas têm o potencial de gerar mudanças nos processos de ensino e aprendizagem, nas formas de interação entre quem aprende e quem ensina e na relação com 0 conhecimento, gerando estratégias pedagógicas inusitadas. Também podem potencializar estratégias reconhecidamente importantes, como a cooperação, o registro e o sentido social dos trabalhos escolares. 
Mas nada disso ocorrerá se forem repetidos, nesses ambientes, os velhos modelos de aprendizagem isola$\mathrm{da}$, de comunicação unidirecional, ou se forem propostas tarefas cuja natureza não seja colaborativa. Nesse caso, a ação resultará em um artificialismo que gera o desinteresse e o baixo aproveitamento dos alunos (Barato, 2005).

Uma faceta marcante das comunidades virtuais está ligada à promoção das relações sociais no âmbito da educação, uma vez que constituem um dos canais mais acessiveis para ampliar e consolidar redes pessoais, incrementando aquilo que sociólogos chamam de "capital social" e que determina as oportunidades culturais, profissionais e até mesmo afetivas das pessoas.

\section{0 que avaliar: recortes e escolhas}

Avaliar significa estabelecer um processo contínuo e permanente que embasa a tomada de decisão quanto a propósitos, processos de ação e alocação de recursos, envolvendo concepção, implementação e resultados do Programa (...). É também um exercício de controle social que possibilita transparência e publicização do Programa nas suas diversas facetas.

MARIA do CARMO BRANT de CARVALHO

A avaliação no EducaRede é um processo sistemático e contínuo, parte integrante das ações desenvolvidas. Considera os conhecimentos acumulados, os referenciais teórico-metodológicos e os objetivos e resultados a serem alcançados. Como todo processo avaliativo, estabelece recortes e escolhas para ganho de relevância e de viabilidade na execução.

Desde antes do lançamento do Portal, desenvolveuse um sistema de monitoramento concebido para registrar permanentemente as informações relevantes sobre o continuum das ações. Em termos quantitativos, o uso do EducaRede tem sido acompanhado por meio de relatórios com os números de páginas vistas, de visitantes únicos, de visitas, de cadastros e de postagens dos usuários nas seções interativas.

As análises dos números alcançados e dos gráficos comparativos, gerados a partir deles, permitem monitorar o impacto das ações e a eficácia das estratégias implantadas. Possibilitam também a previsão de metas e sua adequação aos recursos disponíveis, em termos de acessos e disseminação do Portal. A análise do cadastro dos participantes propicia o acompanhamento do perfil dos usuários, explicitando a assertividade do público a que se destina a iniciativa: a rede de educação pública brasileira.

Em termos qualitativos, a avaliação tem utilizado estratégias diversificadas para coletar informações que organizam e explicitam elementos que possam ajudar na tarefa de aferir a pertinência das ações desenvolvidas. Dentre elas, destacam-se: grupos focais para entrevistas; pesquisas on line com usuários cadastrados; questionários em ações presenciais; estudos de caso.

Todo o processo já implantado favoreceu muitos ensinamentos e permitiu a adequação de ações estratégicas, assim como o melhor entendimento das questões norteadoras relativas à Educação e Internet que direcionam as iniciativas do EducaRede.

Em 2005, visando aprimorar o sistema de monitoramento do Portal, a Fundação Telefônica promoveu entre os parceiros - CENPEC e Fundação Vanzolini - um processo de reflexão que permitiu rever pressupostos, objetivos e conceitos fundamentais da iniciativa, assim como metodologias empregadas até então.

A dinâmica de trabalho incluiu um ciclo de leituras e debates entre as equipes e especialistas convidados, os professores Jarbas Novelino Barato, da Escola do Futuro da USP, e Rogério da Costa, da PUC-SP.

\section{Questões norteadoras que direcionam as iniciativas do Educarede}

\section{Como e quanto o Portal colabora com o uso pedagógi-} co da Internet nas escolas?

Como a utilização sistemática e permanente da Internet e, em especial, do EducaRede, pode trazer benefícios à prática pedagógica na escola?

0 que professores e alunos necessitam para usar a Internet de forma positiva em processos de ensino e aprendizagem?

\section{Quais desses elementos estão presentes?}

Um dos produtos ${ }^{1}$ desse processo foi a construção da Matriz Avaliativa, um recurso gráfico-metodológico que apresenta o arranjo que se estabeleceu entre os elementos, pressupostos, referenciais e estratégias a serem avaliados, delimitando claramente as dimensões e os indicadores de monitoramento e avaliação. 


\section{Matriz avaliativa}

Para construir a Matriz, o EducaRede partiu de sua missão - contribuir para a melhoria da qualidade da educação pública por meio do uso pedagógico da Internet - e definiu dois aspectos fundamentais para alcançá-la. Tais aspectos são apontados como objetivos e se relacionam com a origem, a abrangência e os resultados esperados por meio de sua consecução.

Para cada objetivo, determinou-se uma ou mais "dimensões", traduzidas em "indicadores", que permitem mensurar, de modo conciso e contínuo, os resultados e os avanços. Os "descritores" são coletados em fontes de pesquisa determinadas, como o próprio Portal, softwares específicos para a coleta de acessos e depoimentos de usuários, entre outras.

\section{Objetivos e Dimensões}

- Objetivo 1: tornar público o uso pedagógico da Internet na escola.

Compreende colocar à disposição, democratizar, promover o uso da Internet como espaço de aprendizagem, por meio do EducaRede.

Dimensões: "público usuário do EducaRede" e "redes de relacionamento do EducaRede".

- Objetivo 2: promover aprendizagens relacionadas ao letramento digital: pesquisa, comunicação e publicação.

Dimensões: "ação pedagógica" e "ferramentas tecnológicas”.

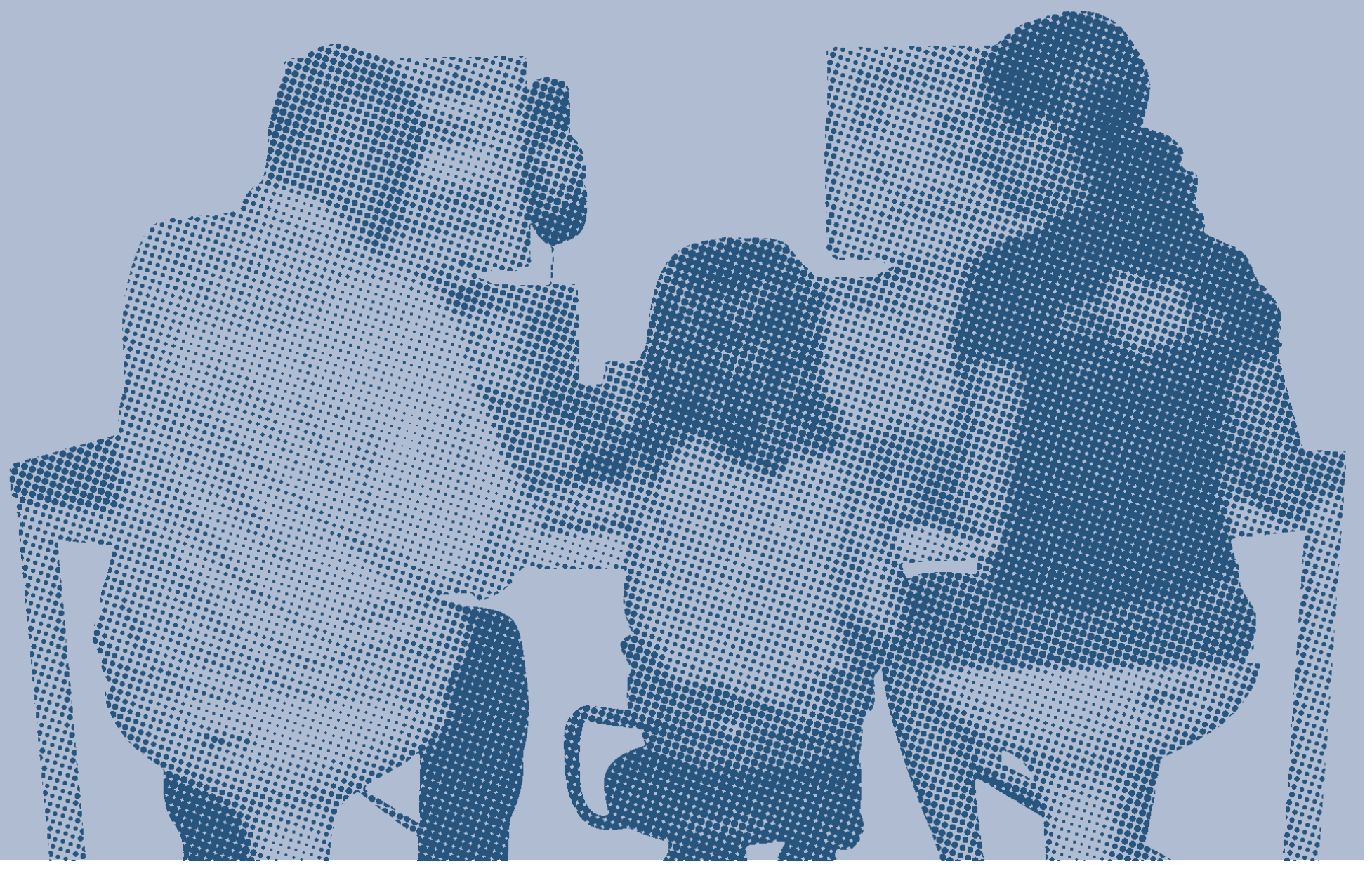


A Matriz Avaliativa foi construída a partir dos valores e princípios certificados pelos parceiros do EducaRede, portanto, está impregnada dos valores presentes nas concepções de Educação e Internet que permeiam a iniciativa. Seu processo de elaboração foi deliberado, no sentido de perseguir os objetivos e a missão. Isso significa que a Matriz tem sentido político, ético e valorativo, como qualquer processo avaliativo.

Sabe-se, no entanto, que os valores indicados não são os únicos. Contudo, muitos indicadores e descritores apontados na Matriz podem contribuir para a reflexão de outras ações de uso pedagógico da Internet e de inclusão digital.

Ao leitor interessado, sugerimos consultar a matriz de avaliação do EducaRede no volume 1 da Coleção EducaRede, páginas 44 a 48, disponível para consulta e impressão no Portal EducaRede 〈www.educarede.org.br 〉.

\section{Letramento Digital}

Um uso aprimorado da Internet remete à compreensão de sua utilidade como instrumento pedagógico no desenvolvimento de aprendizagens relacionadas à pesquisa (buscar, selecionar e analisar informações), comunicação digital (trabalho em rede e a distância) e publicação de materiais (postura ativa e autoral).

\section{Referências}

BARATO, Jarbas N. Internet e educação nas sociedades da informação e da imagem. Processo de Avaliação do Programa EducaRede, São Paulo, 2005.

BELTRÁN LLERA, Jesús A. Enseñar a aprender: algunas reflexiones. In: EDUCARED. Enseñar a aprender: Internet en educación. Madri: Fundación Telefonica, 2004.

BUZATO, Marcelo. O letramento eletrônico e o uso do computador no ensino de língua estrangeira: o caso Tereza. Disponível em: 〈http://www.educarede. org.br/educa/img_conteudo/letramento_eletronico.htm>. Acesso em: 29 mar. 2006.

CARVALHO, Maria do Carmo B. de. Avaliação de projetos sociais. In: ÁVILA, Célia M. (Coord.). Gestão de projetos sociais. São Paulo: AAPCS, 2001.

CASSOL, Márcio B. F.; PRIMO, Alex F. T. Explorando o conceito de interatividade: definições e taxonomias. Disponível em: 〈http://www.psico.ufrgs. br/ aprimo/pb/pgie.htm . Acesso em: 29 mar. 2006.

CASTELLS, Manuel. A galáxia da Internet: reflexões sobre a Internet, os negócios e a sociedade. Rio de Janeiro: Jorge Zahar, 2003.

CHIAPINNI, Lígia. A reinvenção da catedral. São Paulo: Cortez, 2005.

CITELLI, Adilson. Comunicação e educação: a linguagem em movimento. São Paulo: Senac, 2005.
CITELLI, Adilson. Outras linguagens na escola. São Paulo: Cortez, 200o. v. 6. (Col. Aprender e ensinar com textos não-escolares.)

CORTELLA, Mário Sérgio. Feios, sujos e malvados? Folha de S.Paulo, São Paulo, 27/09/2005.

COSTA, Cristina. Ficção, comunicação e mídias. São Paulo: Senac, 2001

COSTA, Rogério da. A promoção da educação através das tecnologias da inteligência. Processo de Avaliação do Programa EducaRede, São Paulo, 2005 .

DAVIS, Cláudia; NUNES, Marina; NUNES, César. Metacognição e sucesso escolar: articulando teoria e prática. Disponível em: 〈http://www.scielo.br/scielo. php?script=sci_arttext\&pid=S0100-15742005000200011\&lng=en\& nrm=iso>. Acesso em: 29 mar. 2006.

DELORS, Jacques (Coord.). Educação, um tesouro a descobrir: relatório para a Unesco da Comissão Internacional sobre Educação para o Século XXI. São Paulo; Brasília: Cortez; Unesco/MEC, 1998.

DIAS, Lia Ribeiro (Coord.). Inclusão digital: com a palavra, a sociedade. São Paulo: Plano de Negócios, 2003.

EDUCAREDE. Vannevar Bush e a idéia original de hipertexto. Disponível em: 〈http://www.educarede.org.br/educa/internet_e_cia/historia.cfm?id_historia $=3$. Acesso em: 30 out. 2005.

FÉRRES, Joan. O uso de tecnologia audiovisual e informática na sala de aula: entrevista. Pátio - Revista Pedagógica, Porto Alegre, n. 9, p. 24-27, 1999. FREIRE, Paulo. Pedagogia do oprimido. Rio de Janeiro: Paz e Terra, 1983.

FUNDAÇÃO GETÚLIO VARGAS. Mapa da exclusão digital. Disponível em: 〈http:// www2.fgv.br/ibre/cps/mapa_exclusao/apresentacao/apresentacao.htm〉. Acesso em: 29 mar. 2006

JANNUZZI, Paulo de Martino. Indicadores sociais no Brasil: conceitos, fontes de dados e aplicações. São Paulo: Alínea, 2001

JOFFILY, Olívia R. Letramento digital e conhecimento. Disponível em: 〈http://www.educarede.org.br/educa/internet_e_cia/informatica. $\mathrm{cfm}$ ?pagina=informatica_principal\&id_inf_escola=14>. Acesso em: 29 mar. 2006.

LÉVY, Pierre. As tecnologias da inteligência: o futuro do pensamento na era da informática. Trad. Carlos Irineu da Costa. Rio de Janeiro: Editora 34, 1993. A Internet tem sido capaz de criar mecanismos próprios de controle das informações. Folha de S.Paulo, Caderno Mais, São Paulo, p. 1-2, abril, $98 \mathrm{f}$. . Educação e cibercultura: a nova relação com o saber. Educação, subjetividade \& poder, Porto Alegre, n. 5, jul. 1998.

MARTÍN-BARBERO, Jesús. Desafios culturais da comunicação à educação. Revista Comunicação \& Educação, São Paulo, n. 18, p. 51-61, maio/set. 2000.

MATTELART, Armand. A globalização da comunicação. Trad. Laureano Pelegrin. Bauru: Edusc, 2000.

OROZCO GÓMEZ, Guillermo. Professor e meios de comunicação: desafios, estereótipos e pesquisas. Comunicação \& Educação, São Paulo, n. 10, p. 57-68, set./dez. 1997.

RIBEIRO, Vera Masagão. Por mais e melhores leitores. In: no Brasil: reflexões a partir do Inaf 2001. São Paulo: Global, 2003.

SANTAELLA, Lúcia. Navegar no ciberespaço: o perfil cognitivo do leitor imersivo. São Paulo: Paulus, 2004.

SILVA, Marco. O que é interatividade. Disponivel em: 〈http://www.senac.br/informativo/BTS/242/boltec242d.htm>. Acesso em: 29 mar. 2006.

SOARES, Magda. Letramento: um tema em três gêneros. Belo Horizonte: Autêntica, 1998.

TRIVINHO, Eugênio. Epistemologia em ruínas: a implosão da teoria da comunicação na experiência do ciberespaço. In: MARTINS, F. M; SILVA, J. M. Para navegar no século XXI: tecnologias do imaginário e cibercultura. Porto Alegre: EDIPUCRS; Sulina, 2000. v. 1 (Col. Comunicação.)

\section{Notas}

1 Foram produzidos textos e um DVD com a edição dos encontros e debates da equipe. 